\title{
Modern Micro-Controllers to Improve the Quality of Production Process
}

doi:10.2478/mape-2021-0019

Date of submission to the Editor: $05 / 2021$

Date of acceptance by the Editor: 06/2021

Dorota Klimecka-Tatar

ORCID ID: 0000-0001-6212-6061

Czestochowa University of Technology, Poland

Tomasz Chajduga

ORCID ID: 0000-0001-6342-7210

Czestochowa University of Technology, Poland
MAPE 2021, volume 4, issue 1, pp. 212-220

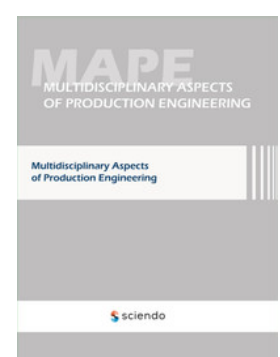

\section{INTRODUCTION}

The production processes are more and more complex. The reason of such situation is twofold. First, the technology is more and more developed (Teo and Too 2000). Second, the approach to stay cost effective makes incentive to regroup the resources, rearrange the processes and perform change after change (Gede et al., 2020). In the world of full computerization and in the era of revolution 4.0, enterprises face a great challenge related to the need to support processes with the use of devices that facilitate the transmission, consumption and generation of digital data. Recent years, or rather the development of computer technologies in recent years, have significantly changed the approach to classic elements of the production system. Customers have become more aware recipients of products and services, and thus customers (consumers) increase their requirements. This situation strongly affects the perception of production and value creation in processes (Ingaldi, 2020). In production, it is no longer sufficient to control and supervise quality, now it is necessary to definitively introduce the principles of quality management. Total integration of quality into the elements of the process. Which, unfortunately, also entails the necessity to overcome numerous technological, economic and social barriers (Kapler, 2021; Żywiolek, et al., 2021).

In general, the better and precise the production process, the better the final product and amount of money generated by the company (Borkowski and Ulewicz, 2009). In the world of increasing pace of technological progress, very important become solutions that are cost-affordable but offer unexpected (until now) precision and capabilities (Alavi and Leidner, 1999).

One of the most innovative technologies are modern micro-controllers that can use key solutions representing new trends, including e.g. artificial intelligence, $5 G$ networks and image recognition as well as neural networks. Anyway, it should be noted that strongly developing technologies are based on the principles of the Internet of Things, smart manufacturing, etc., and all other modern assumptions resulting from Revolution 4.0, which is progressing very 
aggressively throughout the industrial world. The further development of these technologies is predicted to have a huge impact on quality of production and services (Ingaldi, 2018), and, finally, the quality of life.

\section{METHODOLOGY OF RESEARCH}

Methodologically, a scientific approach, logical reasoning and various analytical methods were used to verify that production professionals perceive embedded systems as a modern technology having impact on production quality. The form of the tool was an internet survey. First, the information brochure was distributed to selected individuals (professionals from the area of production) in order to give them more detailed perspective on what modern micro-controllers can do today. Specialists from various production companies were also asked if they believed that the potential of micro-controllers is sufficient to be used in solutions supporting the production processes. The questions asked are presented in Table 1.

Table 1 The questions asked of professionals in the internet survey

\begin{tabular}{|c|l|}
\hline Number of question & \multicolumn{1}{|c|}{ The wording of the question } \\
\hline 1 & $\begin{array}{l}\text { Do you think that modern embedded systems have the } \\
\text { potential to become the technology used to improve the } \\
\text { quality of production? }\end{array}$ \\
\hline 2 & $\begin{array}{l}\text { If you answered "No" for the previous question, please } \\
\text { explain, why do you think so? If you answered "yes" just skip } \\
\text { this question. }\end{array}$ \\
\hline 3 & $\begin{array}{l}\text { Do you think that modern embedded systems will lower } \\
\text { costs of preparing a production line in future? }\end{array}$ \\
\hline 4 & $\begin{array}{l}\text { According to you, which embedded system has the highest } \\
\text { potential in the production area? }\end{array}$ \\
\hline 5 & $\begin{array}{l}\text { Why do you think so? What are the most important aspects, } \\
\text { that make specifically this system the most suitable to be } \\
\text { used in production process? }\end{array}$ \\
\hline 6 & $\begin{array}{l}\text { How do you think, what phases of production can be } \\
\text { perfected by the use of devices with modern micro- } \\
\text { controllers? }\end{array}$ \\
\hline 7 & $\begin{array}{l}\text { Do you think that the company you are working for has the } \\
\text { capabilities to implement, calibrate and use such solutions? }\end{array}$ \\
\hline 8 & $\begin{array}{l}\text { Do you think that you, as a professional in the production } \\
\text { area, could personally implement, calibrate and use such } \\
\text { solution? }\end{array}$ \\
\hline 9 & How many employees does your employer hire? \\
\hline 10 & $\begin{array}{l}\text { What percentage of employees is directly responsible for } \\
\text { production process? }\end{array}$ \\
\hline 11 & \begin{tabular}{l} 
Does your employer is an international company? \\
\hline
\end{tabular} \\
\hline
\end{tabular}

Source: (Own study, 2021).

The answers were collected anonymously among 50 professionals. The sample was collected not randomly taking under consideration the fact of being production professional. The data was processed in June 2021. The questionnaire was distributed via Google Forms tool. 


\section{RESULTS}

The aggregated results of the online survey distributed among production professionals are presented in the Table 2 below.

Table 2 The questions asked of professionals in the internet survey

\begin{tabular}{|c|c|c|}
\hline \multirow{2}{*}{ Question } & \multicolumn{2}{|c|}{ Aggregated answers } \\
\hline & YES & NO \\
\hline $\begin{array}{l}\text { Do you think that modern embedded } \\
\text { systems have the potential to become the } \\
\text { technology used to improve the quality of } \\
\text { production? }\end{array}$ & 48 & 2 \\
\hline $\begin{array}{l}\text { If you answered "No" for the previous } \\
\text { question, please explain, why do you think } \\
\text { so? If you answered "yes" just skip this } \\
\text { question. }\end{array}$ & \multicolumn{2}{|c|}{2 answers given in text } \\
\hline $\begin{array}{l}\text { Do you think that modern embedded } \\
\text { systems will lower costs of preparing a } \\
\text { production line in future? }\end{array}$ & 48 & 2 \\
\hline \multirow{5}{*}{$\begin{array}{l}\text { According to you, which embedded system } \\
\text { has the highest potential in the production } \\
\text { area? }\end{array}$} & STM & 11 \\
\hline & Raspberry PI & 10 \\
\hline & SONY Spresense & 8 \\
\hline & NVIDIA Jetson & 19 \\
\hline & Other & 2 \\
\hline $\begin{array}{l}\text { Why do you think so? What are the most } \\
\text { important aspects, that make specifically this } \\
\text { system the most suitable to be used in } \\
\text { production process? }\end{array}$ & \multicolumn{2}{|c|}{50 short answers given in text } \\
\hline $\begin{array}{l}\text { How do you think, what phases of production } \\
\text { can be perfected by the use of devices with } \\
\text { modern micro-controllers? }\end{array}$ & \multicolumn{2}{|c|}{50 short answers given in text } \\
\hline $\begin{array}{l}\text { Do you think that the company you are } \\
\text { working for has the capabilities to implement, } \\
\text { calibrate and use such solutions? }\end{array}$ & 48 & 2 \\
\hline $\begin{array}{l}\text { Do you think that you, as a professional in } \\
\text { the production area, could personally } \\
\text { implement, calibrate and use such solution? }\end{array}$ & 12 & 38 \\
\hline \multirow{5}{*}{$\begin{array}{l}\text { How many employees does your employer } \\
\text { hire? }\end{array}$} & Hire range & Number of answers \\
\hline & $x<10$ & 7 \\
\hline & $10-50$ & 18 \\
\hline & $51-100$ & 22 \\
\hline & $100<x$ & 3 \\
\hline \multirow{5}{*}{$\begin{array}{l}\text { What percentage of employees is directly } \\
\text { responsible for production process? }\end{array}$} & Percentage range & Number of answers \\
\hline & $x<25 \%$ & 0 \\
\hline & $25-50 \%$ & 15 \\
\hline & $51-75 \%$ & 32 \\
\hline & $75 \%<x$ & 3 \\
\hline $\begin{array}{l}\text { Does your employer is an international } \\
\text { company? }\end{array}$ & 14 & 36 \\
\hline
\end{tabular}

Source: (Own study, 2021)

For the very first question, "Do you think that modern embedded systems have the potential to become the technology used to improve the quality of production?" the vast majority of respondents answered positive - 48 answers what is $96 \%$. The respondents who said "No" argued differently. One responded, that his or her company is already equipped with systems far more sophisticated 
and does not require or expect any changes due to emerging cheap microcontrollers technology. Another person recognized the micro-controllers as not really important because of the hand-made production processes in the company he or she works.

For the question "Do you think that modern embedded systems will lower costs of preparing a production line in future?" the same amount of responded persons sees the potential of modern micro-controllers to lower the production costs $96 \%$. The remaining $4 \%$ are the same persons as in the previous situation described, therefore their opinions are understandable and do not require further clarification.

For the question "which embedded system has the highest potential in the production area?", respondents indicated the NVIDIA Jetson (19 answers). For the question about the reasons, substantiation of one's opinion, respondents indicated the strong computation power and good possibilities to process the data with usage of neural networks and $A I$ that is being more and more often published (Lozhkin, et al., 2021) in NVIDIA solutions (Mittal, 2018).

The next indicated micro-controller solution was STM (11 respondents). They noted that STM is cheap and fast in majority tasks, but could be easier programmable and not only on Windows systems. 10 respondents pointed out the Raspberry PI solution arguing, that it is very easy programmable, not require any special programming language and is very user friendly at affordable price. To be precise, they meant that this solution is already a small computer and programmer can simply run it with his peripherals, f. ex. display, keyboard and mouse at a fraction of a cost of common computer machine. In terms of SONY Spresense, it pointed out 8 respondents, indicating the good quality of Sony products, reliability and user friendly solutions, which are often being described in press (Developer Sony site, 2020). Additionally, two more respondents declared that they know other 2 micro-controllers-based embedded solutions.

In terms of question about the phases of production that can be perfected by the use of devices with modern micro-controllers all possible phases of production were pointed out, from inventory check, through assembly processes and finishing up to the quality check (measurement) of the final product and packing. In the context of the question "Do you think that the company you are working for has the capabilities to implement, calibrate and use such solutions?" the answers were divided 48 to 2 . The 2 respondents that gave the negative answers were exactly the same persons whose explanation was described in terms of the very first question.

Production professionals, when asked if he or she "could personally implement, calibrate and use such solution" answered much more conservative: just 12 respondents out of 50 answered positively - 24\%. The majority (76\%) responded negatively, 38 answers.

In the context of the size of the enterprise that respondents work for, 7 respondents declared that work for company of less than 10 employees, 18 respondents declared to be working for company employing from 10 to 50 
employees, 22 respondents are declaring to be working in bigger companies hiring from 51 up to 100 people and 3 respondents declared to be working in companies hiring more employees.

For the question about the percentage of employees is directly responsible for production process, nobody indicated less than $10 \% .15$ respondents declared that from 25 up to $50 \%$ employees is engaged in production processes. The majority, 32 of respondents (64\% of all) declared that from 51 to $75 \%$ is working in production area. Only 3 persons declared working for the company, where more than $75 \%$ of staff work in production process.

Majority of respondents answered that their employer is an international company - 14 persons, that is $28 \%$ of respondents, while the rest, 36 persons ( $72 \%$ of respondents) claim that their employer is not the international firm.

\section{DISCUSSION}

Taking under consideration all of received responses, the managers of majority of production companies should consider implementing solutions based on modern micro-controllers. These solutions are also important for the idea of industry 4.0 (Pietraszek, et al., 2020). The professionals who work in the production areas do perceive the potential of such solutions. There are studies on how to distinguish the areas for improvements (Klimecka-Tatar and Ingaldi, 2020). Despite the fact of vast majority of positive approach to the modern microcontrollers-based solutions, the authors consider it must be said, that not all the companies shall be interested in the changing their production processes in order to become more oriented on described solutions. First, some companies have already have technology more advanced. In fact, they had to buy it for much more money than similar solutions based on modern micro-controllers would cost. In such cases, regardless of cost effectiveness, the expenses have already been incurred and (for such companies) there is no point to swap the technology for maybe slightly worse but surely far cheaper, mostly due to more and more specialized sensors (Kim et al., 2021). At the other extreme of technological face, there are the companies, that vastly use human workforce or simply prefer handicraft. In those cases, the usage of modern microcontrollers can be very limited. The authors would recommend using it, however. For example, in the handicraft-based company, the modern devices can be used to help the creator to measure, if the final job is in range of tolerance. Moreover, there is a variety of components that can be checked by microcontroller-based devices before they are assembled by man. This way, the human time can be saved, due to automatic checking procedure.

It is also important to point out that the majority of the respondents - production professionals, does not feel enthusiastic about self-implementation, selfcalibration of such solutions. However, it must be stated, that more and more home DIY projects is being created with above mentioned solutions. In the opinion of the authors, the conservative approach of professionals can be the effect of experience with implementation, calibration and maintenance of the 
already known, but far more complex and harder to maintain than modern microcontrollers-based solutions.

\section{CONCLUSION}

The final conclusion in the researched area is that modern micro-controllers have extraordinary potential to lower the cost of solutions used in production processes. The vast majority of experts (professionals) see and admit it. However, not every company should go into it at once. Moreover, there can be some sort of companies or market situations, f. ex. low costs of labor or lack of educated persons on the market-able to maintain the micro-controller-based solutions even to a minimal extent (Grabara et al., 2019). In such situations using this sort of solutions would be inadvisable. On the other hand, modern micro-controllers can be used to better use the existing potential of human capital, f. ex. through activation of disabled people (Knijn and Wel, 2014) or to enforce the core competences of startup companies (Korpysa, 2021). Also, there are possible intermediate cases, f. ex. if the company builds its products as a hand-made (for example luxury cars) or handicraft. In such cases, the solutions based on modern micro-controllers are possible to use as a helping tools to measure the final product of hand work or in order to verify the operation of mounted components. The further research must be made in order to verify much more possible cases, mostly when considering companies, where less than $25 \%$ of employees is responsible for production processes (the research did not cover those cases). Moreover, mostly in case of small-sized companies the aspect of culture should be taken under consideration (Klimecka-Tatar and Niciejewska, 2021). Finally, it must be said, that the scope of usage of microcontrollers is going to grow more and more due to the new, compatible with the micro-controllers, sensors that are emerging on the market.

\section{ACKNOWLEDGEMENTS}

Research and publication were financed by the statutory research fund of the Czestochowa University of Technology SPB-600/3016/2021.

\section{REFERENCES}

Alavi, M., \& Leidner, D.,1999. Knowledge Management Systems: Issues, Challenges, and Benefits. Communications of the Association for Information Systems, 1., https://doi.org/10.17705/1CAIS.00107

ARM Webpage, (accessed: 02.12.2020), https://www.arm.com/

Bilan, Y., Hussain, H. I., Haseeb, M., \& Kot, S., 2020. Sustainability and Economic Performance: Role of Organizational Learning and Innovation, Engineering Economics, 31(1), pp. 93-103. https://doi.org/10.5755/j01.ee.31.1.24045

Borkowski, S., Ulewicz, R., 2009. Instruments of Production Processes Improvement, PTM, Warszawa.

Chajduga, T., 2021. Embedded systems ensuring safety for people with disabilities, System Safety: Human - Technical Facility - Environment, 3(1), (in press).

Chmielarz, G., 2019. Present state and future application of smart technologies in manufacturing processes, Production Engineering Archives, 24(24), pp. 14-19. https://doi.org/10.30657/pea.2019.24.04 
Edge computing with low power consumption, (accessed: 11.12.2020), https://developer.sony.com/develop/spresense/

Embedded systems, Omni Sci, (accessed: 11.12.2020), https://www.omnisci.com/technical-glossary/embedded-systems

Frăticiu, L., Mihăescu, D., \& Andănuţ, M., 2015. Culture-Civilization-Organizational Culture and Managerial Performance, Procedia Economics and Finance, 27, pp. 69-72. https://doi.org/10.1016/S2212-5671(15)00973-9

Frustaci, F., Perri, S., Cocorullo, G., \& Corsonello, P., 2020. An embedded machine vision system for an in-line quality check of assembly processes, Procedia Manufacturing, 42(1-3), pp. 211-218. https://doi.org/10.1016/j.promfg.2020.02.072

Gede Riana, I., Suparna, G., Gusti Made Suwandana, I., Kot, S., \& Rajiani, I., 2020. Human resource management in promoting innovation and organizational performance, Problems and Perspectives in Management, 18(1), pp. 107-118. https://doi.org/10.21511/ppm.18(1).2020.10

Grabara, J., Cehlar, M., \& Dabylova, M., 2019. Human factor as an important element of success in the implementation of new management solutions, Polish Journal of Management Studies, 20(2), pp. 225-235. https://doi.org/10.17512/pjms.2019.20.2.19

Ingaldi, M., 2018., Overview of the main methods of service quality analysis, Production Engineering Archives, 18(18), pp. 54-59. https://doi.org/10.30657/pea.2018.18.10

Ingaldi, M., 2020., A new approach to quality management: Conceptual matrix of service attributes Polish Journal of Management Studies, 22(2), pp. 187-200. https://doi.org/ 10.17512/pjms.2020.22.2.13

Kapler, M., 2021, Barriers to the implementation of innovations in information systems in SMEs. Production Engineering Archives, 27(20, pp. 156-162. https://doi.org/10.30657/pea.2021.27.20

KAMAMI oficjalnym partnerem STMICROELECTRONICS, (accessed: 10.12.2020), https://stm32.eu/

Kim, J., Lee, S., Chun, H., \& Lee, C., 2021. Compact curved-edge displacement sensorembedded spindle system for machining process monitoring. Journal of Manufacturing Processes, 64(12), pp. 1255-1260. https://doi.org/10.1016/j.jmapro.2021.02.056

Klimecka-Tatar, D., \& Ingaldi, M., 2020. How to indicate the areas for improvement in service process - the Knowledge Management and Value Stream Mapping as the crucial elements of the business approach, G\&T, Revista Gestão \& Tecnologia, 20(2), pp. 52-74. https://doi.org/10.20397/2177-6652/2020.v20i2.1878

Klimecka-Tatar, D., \& Niciejewska, M., 2021. Small-sized enterprises management in the aspect of organizational culture, G\&T, Revista Gestão \& Tecnologia, 21(1), pp. 4-24. https://doi.org/10.20397/2177-6652/2021.v21i1.2023

Knijn, T., \& van Wel, F., 2014. Better at work: Activation of partially disabled workers in the Netherlands, Alter, 8(4), 282-294. https://doi.org/10.1016/j.alter.2014.09.005

Korpysa, J., 2021. Process Ambidexterity in Startups Innovation, Management Systems in Production Engineering, 29(1), pp. 27-32. https://doi.org/10.2478/mspe-2021-0004

Lazar, S., Klimecka-Tatar, D., \& Obrecht, M., 2021. Sustainability Orientation and Focus in Logistics and Supply Chains, Sustainability, 13(6), 3280. https://doi.org/10.3390/su13063280

Liu, J., \& Feng, J., 2021. Design of embedded digital image processing system based on ZYNQ, Microprocessors and Microsystems, 83(1), 104005. https://doi.org/10.1016/j.micpro.2021.104005

Lozhkin, A., Maiorov, K., \& Bozek, P., 2021. Convolutional Neural Networks Training for Autonomous Robotics, Management Systems in Production Engineering, 29(1), pp. 75-79. https://doi.org/10.2478/mspe-2021-0010 
Matuszny, M., 2020. Building decision trees based on production knowledge as support in decision-making process, Production Engineering Archives, 26(2), pp. 36-40. https://doi.org/10.30657/pea.2020.26.08

Mittal, S., 2018, A Survey on Optimized Implementation of Deep Learning Models on the NVIDIA Jetson Platform, (accessed: 10.12.2020),

https://www.researchgate.net/publication/329802520_A_Survey_on_Optimized_Imple mentaion_of_Deep_Learning_Models_on_the_NVIDIA_Jetson_Platform

NVIDIA Jetson TX2 Tegra Developer Kit, (accessed: 11.12.2020), https://www.precisioncomputers.com.au/nvidia-jetson-tx2-tegra-developer-kit/

Pietraszek, J., Radek, N., \& Goroshko, A. V., 2020. Challenges for the DOE methodology related to the introduction of Industry 4.0, Production Engineering Archives, 26(4), pp. 190-194. https://doi.org/10.30657/pea.2020.26.33

Raspberry Pi 400 - Your complete personal computer built into a compact keyboard, (accessed: 10.12.2020), https://www.raspberrypi.org/

$\begin{array}{lllll}\text { Raspberry } & \text { Pi GPIO pins. (accessed: } & 11.12 .2020)\end{array}$ https://forum.arduino.cc/index.php?topic $=539419.0$

Schwenk, C. H., 1986. Information, Cognitive Biases, and Commitment to a Course of Action, Academy of Management Review, 11(2), pp. 298-310. https://doi.org/10.5465/amr.1986.4283106

Teo, T. S.H., \& Too, B. L., 2000. Information Systems Orientation and Business Use of the Internet: An Empirical Study, International Journal of Electronic Commerce, 4(4), pp. 105-130. https://doi.org/10.1080/10864415.2000.11518381

Tkachenko, V., Klymchuk, M., \& Tkachenko, I., 2021. Recursive and Convergence Methodology of the Investment Management of the Enterprise Digitalization Processes, Management Systems in Production Engineering, 29(1), pp. 14-19. https://doi.org/10.2478/mspe-2021-0002

Valvano, J.W. PhD, 2017. Embedded systems: introduction to arm cortex-m microcontrollers (accessed: 11.12.2020) http://users.ece.utexas.edu/ valvano/arm/outline1.htm

Zhang, K., 2021, Animation virtual reality scene modeling based on complex embedded system and FPGA, Microprocessors and Microsystems, 80(1), 103632. https://doi.org/10.1016/j.micpro.2020.103632

Zhou, J., 2020. Real-time task scheduling and network device security for complex embedded systems based on deep learning networks, Microprocessors and Microsystems, 79(1), 103282. https://doi.org/10.1016/j.micpro.2020.103282

Żywiołek, J., Rosak-Szyrocka, J., Jereb, B. 2021, Barriers to Knowledge Sharing in the Field of Information Security, Management Systems in Production Engineering 29(2): pp. 114-119. https://doi.org/10.2478/mspe-2021-0015 
Abstract: In general, the production processes are more and more complex. This is the result of more and more sophisticated materials used, the pressure to save them as well as other production resources (ecological perspective), also the tendency to buy mobile products lighter and less power consuming than before. In previous years using highly specialized technology was very costly for the company. Nowadays, this situation is possible to be changed because of emerging types of modern microcontrollers and variety of compatible sensors. Some of those micro-controllers are more power saving, some are more powerful in terms of computing power. The common denominator is that both purchasing them as well as programming is possible for ordinary person, a hobbyist building DIY projects. This sheds new light to the professional usage of modern micro-controllers-based solutions that can become possible to offer comparable level of precision at the fraction of cost. The authors recognized the strong potential in modern micro-controllers and made the research among professionals in the area of production companies. The outcome of research showed that the professionals share the opinion of the authors. Therefore, the outbreak of usage of such inexpensive solutions in professional applications is expected. However, the research showed, that there is possible to find single situations, where usage of modern micro-controllers may be limited, for example in the company targeted to produce hand-made products or handicraft (manufacture).

Keywords: automation solutions, embedded systems, assembly supporting technologies, production assistive technologies 